\title{
Programmable calculator as timer, storer, and decision maker in psychology experiments
}

\author{
MARSHALL M. HAITH and BENNETT BERTENTHAL \\ University of Denver, Denver, Colorado 80208
}

\begin{abstract}
This paper describes how a portable programmable calculator can be used to time behavior, to store time values from successive trials, and to perform criterial calculations on a trial-bytrial basis. A specific application for visual habituation studies in infants is described and an exemplary program, currently in use, is listed.
\end{abstract}

Many situations in psychology require timing of behaviors over several successive trials. Often the behavior of interest is timed by an observer with a stopwatch or timer, and time values are recorded after each trial. A more complex situation occurs when intertrial computations are required. An example is habituation studies for which a subject-defined criterion is used. This adaptation requires a determination of an initial baseline, a calculation of a moving average over the last $\mathrm{n}$ trials, and a comparison between baseline and moving average to determine if criterion has been met. When the criterion is met, a new experimental phase is introduced.

For such applications, the experimenter has the choice of using a stopwatch or timer and an observer who records durations from trial to trial; the observer or another person must perform the needed calculations between trials. This procedure places limits on the rate at which trials can be presented, and it is error prone. Other alternatives, such as microprocessors or minicomputers, have been used to time and store the successive trial durations as well as to carry out the intertrial calculations (Caron, Caron, \& Carlson, in press; Celhoffer, Boukydis, Minde, \& Muir, 1977; Scott \& Masi, 1977). However, such equipment is fairly expensive, relatively difficult to program, and often too bulky for field applications. An alternative is a highly portable handcalculator which may be programmed to do the job.

Consider a current paradigm, which is used fairly widely for habituation research with human infants. The behavior of interest is the duration of the baby's first fixation of a stimulus. A subject-defined criterion of habituation is established as follows. An initial looking baseline is defined as the average looking time on the first three trials. The subject is said to have reached criterion when the average looking time on three successive trials drops below $50 \%$ of baseline. An exception is made for short lookers; the criterion cannot be less

The application described here was developed under NIMH Grant MH 23412 to M. Haith. We thank Dan Maddox for designing the calculator cradle described in Figure 1 and Betty Richardson for preparing the manuscript. than $6 \mathrm{sec}$ (for the three-trial sum). When criterion is met, a dishabituating stimulus is presented. To evaluate the role of spontaneous regression in our own experiments, half of our subjects do not receive the dishabituation stimulus until two trials after criterion is met (lag condition).

The instrumentation must be able to: (1) time looking duration on each trial, (2) store the time values for later recovery, (3) perform the $50 \%$ or 6 -sec criterion calculations, (4) determine if a lag condition is in effect, and (5) inform the experimenter when the dishabituation trials should begin. A program is shown below which performs these calculations on an HP-67 calculator. Lag and nonlag conditions are accommodated, and an error routine to correct for false starts is included. The calculator currently sells for around $\$ 360$. $^{1}$

\section{EXPERIMENTAL SEQUENCE}

In testing a subject in our current experiments, the following sequence occurs. The calculator is turned on with the "W/Prgm-Run" switch to "Run." The program card is passed through the calculator first for Side 1 and then for Side 2. To start the program, either the $\mathrm{D}$ or $\mathrm{E}$ button is pressed for lag and nonlag conditions, respectively. A display of " 1 " appears, indicating that the calculator is ready to time behavior for Trial 1 . Timing begins when the R/S button is pressed and stops when it is pressed again. (Actually, any keypress will terminate timing.) The time value for Trial 1 appears in the display (in the form of 20 counts/sec) with no zeroes to the right of the decimal (significance explained below). When the A button is pressed, the value is stored and calculations are performed. Then a " 2 " appears in the display to indicate that Trial 2 is next, and the process repeats. Once criterion is reached (or two trials later for the lag condition), the calculator displays all numbers with eight zeroes to the right of the decimal. The extended display cues the experimenter to begin the dishabituation phase. Up to 24 trials may be stored in this way. When Trial 24 is completed, "CRD" is displayed; a magnetic card can then be passed through the calculator to record the time values for the first 24 
trials, and the experimenter can proceed to record additional trials. (The times for the first three trials and the last two trials are preserved for criterion calculations.) After the experiment is completed, the REG button is pressed to display the contents of the storage registers for $2 \mathrm{sec}$ each, so they may be permanently recorded. Following is additional detail on the timing, calculation, and logic sequence.

\section{Timing}

Timing begins when the start button is pressed. A " + " operation is carried out 100 times in succession (between Program Steps 26 and 126), at which time the loop begins anew and continues until a button is pressed. ${ }^{2}$ Since a " 1 " is entered into the stack registers before each trial (Steps 17-20), each " $t$ " operation increments the displayed count by one. The time required for this operation is quite stable but might vary from unit to unit. On our calculator, each " + " operation requires about $50 \mathrm{msec}$, so we accrue about 20 counts $/ \mathrm{sec}^{3}$ At the end of the timing interval, the count is divided by 20 (Steps 135-137) so that the actual time, in seconds, is stored (Step 138). This value may have to be changed slightly for individual units after the timing has been calibrated.

\section{Storage}

The time values are stored in successive memory registers as follows. Storage Register 0 holds the current trial count during timing. When the A button is pressed at the end of a trial, the trial count is placed in the I register (Program Steps 131 to 133), whose contents can be used as an indirect address for a storage register. Then, the actual duration for the current trial is deposited in the storage register whose number corresponds to the trial number. [This is done through the indirect-store command which uses Register I (Step 138)].

\section{Calculation}

The calculation routines consume less than $2 \mathrm{sec}$ between trials, except for precriterion trials after Trial 3 which require about $3.5 \mathrm{sec}$. A branch is first made depending on whether criterion has been met on prior trials, as indicated by Flag 1 being set (Step 139).

Precriterion branch $(F 1=0)$. If the criterion has not been met on prior trials the following determinations are made:
(1) Have four or more trials occurred? (Steps 146-148.) If not, all the following steps are skipped and preparation is made for the next trial (Steps 16-23).

(2) Has criterion been met? This test is made by first determining if looking on the last three trials sums to less than $6 \mathrm{sec}$ (Steps 160-163). If not, the sum of times on the last three trials is compared to $50 \%$ of the sum on the first three trials (Steps 174-182). If it is greater than $50 \%$, the following steps are skipped, and preparation is made for the next trial (Steps 197-202 and 16-23).

\section{Postcriterion branch (F1=1).}

(1) If Flag 1 was set on a prior trial, the calculator quickly branches (Steps 139-140) to determine if all storage registers have been used (Steps 197-202); then it sets up for the next trial (Steps 16-23).

(2) If criterion was just met on the current trial, a check is first made to determine if the subject is in the lag condition (Steps 186-187). If not, Flag 1 is set, and the calculator is instructed to display eight digits (Steps 147-202 and 16-23).

(3) If a lag condition is in effect, the calculator avoids a display change (Steps 189-190) and then waits two additional trials before changing the display (Steps 192 and 141-144).

For both precriterion and postcriterion conditions, preparation for the next trial includes a check for whether all 24 storage registers have been used (Steps 197-202). If so, the calculator displays "CRD" (Step 204) to prompt the experimenter to record the contents of all the storage registers on a magnetic card. Finally, an error routine is provided in the program. If the $\mathrm{R} / \mathrm{S}$ button is pressed accidentally to start timing, the operator can stop timing (by pressing $R / S$ again) and then press $B$, which reinstates the calculator to its normal state for the next trial (Steps 215-219). If the $\mathrm{R} / \mathrm{S}$ button is accidentally pressed during timing, which stops the calculator, timing may be resumed by simply repressing the $\mathrm{R} / \mathrm{S}$ button. This description touches on only the major features of the program. For more detail the interested reader should consult the program listing in Table 1 and the user instructions for operating the program in Table 2.

\section{LIMITATIONS}

One problem in using a calculator for timing is that the calculator can detect only mechanical keypresses.

Table 1

Keypress, Operation Sequence, and Documentation for the Timer and Calculation Program

\begin{tabular}{llllll}
\hline $\begin{array}{c}\text { Section } \\
\text { Function }\end{array}$ & Step & $\begin{array}{c}\text { Key } \\
\text { Entry* }\end{array}$ & $\begin{array}{c}\text { Actual } \\
\text { Operation }\end{array}$ & $\begin{array}{c}\text { Calculator } \\
\text { Code }\end{array}$ & Comment \\
\hline Nonlag Condition & 001 & f SST D & LBL D & 312514 & Statement D \\
& 002 & h -0 & SF O & 355100 & Indicate nonlag condition by setting Flag 0 \\
Preparation: & 003 & f SST E & LBL E & 312515 & Statement E \\
Clear flags & 004 & h +1 & CF 1 & 356101 & Clear Flag 1 (criterion flag) \\
and storage & 005 & & DSP O & 2300 & Display no zeroes to right of decimal
\end{tabular}


Table 1 Con tinued

\begin{tabular}{|c|c|c|c|c|c|}
\hline $\begin{array}{c}\text { Section } \\
\text { Function }\end{array}$ & Step & $\begin{array}{c}\text { Key } \\
\text { Entry* }\end{array}$ & $\begin{array}{c}\text { Actual } \\
\text { Operation }\end{array}$ & $\begin{array}{c}\text { Calculator } \\
\text { Code }\end{array}$ & Comment \\
\hline registers. Set & 006 & f EEX & CL REG & 3143 & Clear Storage Registers $0-9,20-24$ \\
\hline up timing & 007 & f CHS & $\mathrm{P} \gtrless \mathrm{S}$ & 3142 & Exchange primary and secondary registers \\
\hline \multirow[t]{7}{*}{ loop count } & 008 & f EEX & CL REG & 3143 & Clear former Storage Registers 10-19 \\
\hline & 009 & & 1 & 01 & Prepare negative value \\
\hline & 010 & & 0 & 00 & for repeating timing \\
\hline & 011 & & 0 & 00 & loop (between Steps 026-126) \\
\hline & 012 & & CHS & 42 & \\
\hline & 013 & & STO 0 & 3300 & Store loop count value in Register 0 \\
\hline & 014 & $\mathrm{~h} \mathbf{R} / \mathrm{S}$ & SPACE & 3584 & no operation \\
\hline \multirow[t]{17}{*}{ Timing } & 015 & f SST 1 & LBL 1 & 312501 & Statement 1 \\
\hline & 016 & f RCL & ISZ & 3134 & Increment the trial number in Register 1 \\
\hline & 017 & & 1 & 01 & Fill stack with the add constant of 1 \\
\hline & 018 & & ENTER & 41 & \\
\hline & 019 & & ENTER & 41 & \\
\hline & 020 & & ENTER & 41 & \\
\hline & 021 & & $\mathrm{RCL} \mathrm{O}$ & 3400 & Display the loop count $(-100)$ \\
\hline & 022 & h (i) & $X \gtrless 1$ & 3524 & Put the loop count in Register I. Display trial no. \\
\hline & 023 & & STO O & 3300 & Store the trial number in Register 0 \\
\hline & 024 & & $\mathrm{R} / \mathrm{S}$ & 84 & Stop. Wait for keypress of R/S \\
\hline & 025 & & CLX & 44 & Clear the display \\
\hline & 026 & & + & 61 & Add 1 to the display \\
\hline & $\downarrow$ & & + & 61 & Repetitively (100 times) \\
\hline & 125 & & + & 61 & \\
\hline & 126 & & GTO (i) & 2224 & GO TO STEP 026; continue adding until $R / S$ is pressed \\
\hline & 127 & $h \mathrm{R} / \mathrm{S}$ & SPACE & 3584 & No operation \\
\hline & 128 & $\mathrm{~h} R / \mathrm{S}$ & SPACE & 3584 & No operation \\
\hline \multirow[t]{10}{*}{ Time Storage } & 129 & f SST A & LBL A & 312511 & Statement $A$ \\
\hline & 130 & & ENTER & 41 & Copy timing count in Register $Y$ \\
\hline & 131 & & RCL O & 3400 & Display the trial no. \\
\hline & 132 & h (i) & $X \geq I$ & 3524 & Put the trial no. in Register I and display the loop count \\
\hline & 133 & & STOO & 3300 & Store the loop count in Register 0 \\
\hline & 134 & h 8 & $\mathrm{Rv}$ & 3553 & Display the timing count \\
\hline & 135 & & 2 & 02 & Divide the time count \\
\hline & 136 & & 0 & 00 & by 20 to get \\
\hline & 137 & & $\div$ & 81 & real time \\
\hline & 138 & & STO (i) & 3324 & Store the time in the current trial register number \\
\hline Criterion and & 139 & $\mathrm{~h} \times 1$ & F? 1 & 357101 & Has criterion been met? \\
\hline Minimal Trial & 140 & & GTO 6 & 2206 & Yes, GO TO STATEMENT 6 (STEP 197) \\
\hline \multirow[t]{10}{*}{ Check } & 141 & $\mathrm{~h} \times 2$ & F? 2 & 357102 & Is this Lag Trial 1 ? \\
\hline & 142 & & GTO 4 & 2204 & Yes, GO TO STATEMENT 4 (STEP 191) \\
\hline & 143 & $\mathrm{~h} \times 3$ & $F ? 3$ & 357103 & No, is this Lag Trial $2 ?$ \\
\hline & 144 & & GTO 5 & 2205 & Yes, GO TO STATEMENT 5 (STEP 194) \\
\hline & 145 & h RCL & $\mathrm{RC} I$ & 3534 & No, display the current trial number \\
\hline & 146 & & 3 & 03 & Have more than three trials occurred? \\
\hline & 147 & & - & 51 & \\
\hline & 148 & $f \div$ & $X>0$ & 3181 & \\
\hline & 149 & & GTO 2 & 2202 & Yes, GOTO STATEMENT 2 (STEP 151) \\
\hline & 150 & & GTO 1 & 2201 & No, GO TO STATEMENT 1 (STEP 015) \\
\hline Criterion, & 151 & f SST 2 & LBL 2 & 312502 & Statement 2 \\
\hline \multirow{18}{*}{$\begin{array}{l}\text { Calculation, } \\
\text { and } \\
\text { Comparison }\end{array}$} & 152 & & RCL (i) & 3424 & Display the time recorded for the current trial \\
\hline & 153 & f STO & DSZ & 3133 & Decrement Register I (the trial count) by 1 \\
\hline & 154 & & $\mathrm{RCL}$ (i) & 3424 & Display the time recorded for the preceding trial \\
\hline & 155 & & + & 61 & Sum the times for the last two trials \\
\hline & 156 & f STO & DSZ & 3133 & Decrement Register I (the trial count) by 1 \\
\hline & 157 & & RCL (i) & 3424 & Display the time recorded two trials ago \\
\hline & 158 & & + & 61 & Sum the times for the last three trials \\
\hline & 159 & & ENTER & 41 & Copy the sum in Register $Y$ \\
\hline & 160 & & 6 & 06 & Is the sum less than 6 sec? \\
\hline & 161 & & - & 51 & \\
\hline & 162 & $f x$ & $\bar{x}<0$ & 3171 & \\
\hline & 163 & $h-1$ & SF 1 & 355101 & Yes, set Flag 1, the criterion flag \\
\hline & 164 & & 6 & 06 & Restore the time sum for the \\
\hline & 165 & & + & 61 & last three trials \\
\hline & 166 & & ENTER & 41 & Copy the sum in Register $Y$ \\
\hline & 167 & h RCL & RC I & 3534 & Restore the trial count in \\
\hline & 168 & & 2 & 02 & Register I \\
\hline & 169 & & + & 61 & \\
\hline
\end{tabular}


Table 1 Continued

\begin{tabular}{|c|c|c|c|c|c|}
\hline $\begin{array}{l}\text { Section } \\
\text { Function }\end{array}$ & Step & $\begin{array}{c}\text { Key } \\
\text { Entry* }\end{array}$ & $\begin{array}{c}\text { Actual } \\
\text { Operation }\end{array}$ & $\begin{array}{c}\text { Calculator } \\
\text { Code }\end{array}$ & Comment \\
\hline & 170 & h STO & ST 1 & 3533 & \\
\hline & 171 & $\mathrm{~h} \times 1$ & $\mathrm{~F} ? 1$ & 357101 & Is Flag 1 set? (i.e., was the $6-\sec$ criterion met?) \\
\hline & 172 & & GTO 3 & 2203 & Yes, GO TO STATEMENT 3 (STEP 185) \\
\hline & 173 & & CL $\mathrm{X}$ & 44 & No, clear the display \\
\hline & 174 & & RCL 1 & 3401 & Calculate $50 \%$ of the looking \\
\hline & 175 & & RCL 2 & 3402 & time on the first three trials \\
\hline & 176 & & + & 61 & \\
\hline & 177 & & RCL 3 & 3403 & \\
\hline & 178 & & + & 61 & \\
\hline & 179 & & 2 & 02 & \\
\hline & 180 & & $\div$ & 81 & \\
\hline & 181 & & - & 51 & Is the looking time in the last \\
\hline & 182 & $f x$ & $\mathrm{X}<0$ & 3171 & three trials less than this value? \\
\hline & 183 & & GTO 3 & 2203 & Yes, GO TO STATEMENT 3 (STEP 185) \\
\hline & 184 & & GTO 6 & 2206 & No, GO TO STATEMENT 6 (STEP 197) \\
\hline Lag Condition & 185 & f SST 3 & LBL 3 & 312503 & Statement 3 \\
\hline \multirow[t]{8}{*}{ Check } & 186 & $h+1$ & CF 1 & 356101 & Clear Flag 1 (if set by $6-\mathrm{sec}$ criterion) \\
\hline & 187 & $\mathrm{~h} \times 0$ & F? 0 & 357100 & Is this the nonlag condition? \\
\hline & 188 & & GTO 5 & 2205 & Yes, GO TO STATEMENT 5 (STEP 194) \\
\hline & 189 & $h-2$ & SF 2 & 355102 & No, set Flag 2 denoting next trial is Lag 1 \\
\hline & 190 & & GTO 6 & 2206 & GO TO STATEMENT 6 (STEP 197) \\
\hline & 191 & f SST 4 & LBL 4 & 312504 & Statement 4 \\
\hline & 192 & $h-3$ & SF 3 & 355103 & Set Flag 3 denoting next trial is Lag 2 \\
\hline & 193 & & GTO 6 & 2206 & GO TO STATEMENT 6 (STEP 197) \\
\hline Adjust display & 194 & f SST 5 & LBL 5 & 312505 & Statement 5 \\
\hline to indicate & 195 & $h-1$ & SF 1 & 355101 & Set Flag 1 \\
\hline \multirow[t]{2}{*}{ criterion met } & 196 & & DSP 8 & 2303 & Display eight zeroes to right of decimal \\
\hline & 197 & f SST 6 & LBL 6 & 312506 & Statement 6 \\
\hline Determine if all & 198 & h RCL & $\mathrm{RC} 1$ & 3534 & Display the trial count \\
\hline 24 storage & 199 & & 2 & 02 & Have 24 trials been presented? \\
\hline registers are & 200 & & 4 & 04 & \\
\hline full; if so, & 201 & & - & 51 & \\
\hline cue the & 202 & $f+$ & $X \neq 0$ & 3161 & \\
\hline \multirow[t]{11}{*}{ operator } & 203 & & GTO 1 & 2201 & No, GO TO STATEMENT 1 (STEP 015) \\
\hline & 204 & f ENTER & W/DATA & 3141 & Yes, display "CRD." Wait for data to be recorded \\
\hline & 205 & & 5 & 05 & Reset current trial count \\
\hline & 206 & h STO & ST I & 3533 & to 5 \\
\hline & 207 & & RCL D & 3414 & Preserve the data from the first \\
\hline & 208 & & STO 4 & 3304 & three trials and the last two trials \\
\hline & 209 & & RCL E & 3415 & for criterion calculations. Keep \\
\hline & 210 & & STO 5 & 3305 & the information in Registers $1-5$. \\
\hline & 211 & & GTO 1 & 2201 & GO TO STATEMENT 1 (STEP 015) \\
\hline & 212 & h R/S & SPACE & 3584 & No operation \\
\hline & 213 & h R/S & SPACE & 3584 & No operation \\
\hline Error routine to & 214 & f SST B & LBL B & 312512 & Statement B \\
\hline restore status & 215 & & RCL 0 & 3400 & Display current trial count \\
\hline after false & 216 & & 1 & 01 & Reduce trial count \\
\hline timing start & 217 & & - & 51 & by 1 \\
\hline & 218 & h (i) & $\mathrm{X} \geq \mathrm{I}$ & 3524 & Display loop count. Put trial count in Register $I$. \\
\hline & 219 & & STO 0 & 3300 & Store the loop count in Register 0 \\
\hline & 220 & & GTO 1 & 2201 & GO TO STATEMENT 1 (STEP 015) \\
\hline Unused & 221 & & $\mathrm{R} / \mathrm{S}$ & 84 & \\
\hline & 222 & & $\mathrm{R} / \mathrm{S}$ & 84 & \\
\hline & 223 & & $\mathrm{R} / \mathrm{S}$ & 84 & \\
\hline & 224 & & $\mathrm{R} / \mathrm{S}$ & 84 & \\
\hline
\end{tabular}

*Entry only shown when it differs from actual operation key.

One cannot activate or stop the timer by completely electronic means, which makes it difficult to synchronize the timer-calculator to other experimental events. We have overcome at least one problem with this limitation in an application which required synchronization between the calculator time, a slide projector, and the event pen of a polygraph. A cradle was constructed for the calculator with a horizontal bar guided by pins that permitted no vertical play (see Figure 1). When pressed, the bar simultaneously activated the $\mathrm{R} / \mathrm{S}$ button and an electronic switch. The switch controlled the event pen on the polygraph and an electronic shutter 
Table 2

User Instructions for Operating Program

\begin{tabular}{|c|c|c|c|}
\hline Step & Instructions & Keys & Output Data/Units \\
\hline 1 & Turn on calculator with "Run" on. & & \\
\hline 2 & Press D or E to start program. Display trial number. & $\mathrm{D}$ or $\mathrm{E}$ & 1 \\
\hline 3 & Press $\mathrm{R} / \mathrm{S}$ to start timing. & $\mathrm{R} / \mathrm{S}$ & \\
\hline 4 & Press R/S to stop timing. (Display number of counts) & $\mathrm{R} / \mathrm{S}$ & $\mathrm{nnn}$ \\
\hline 5 & Press A to store and calculate. Then display trial number. & A & 2 \\
\hline 6 & Repeat Steps 3-5 to Trial 24 & & \\
\hline 7 & When "CRD" is displayed, pass a new card through reader on both sides. & & \\
\hline 8 & Repeat Steps 3-7 until experiment is over. & & \\
\hline 9 & Press "h 3" to review Memory Registers 0-9, 20-25. & h 3 & Storage $0-9,20-25$ \\
\hline 10 & Press "f CHS" to exchange primary and secondary registers. & f CHS & \\
\hline 11 & Press "h 3" to review Memory Registers 10-19 & h 3 & Storage $10-19$ \\
\hline 12 & If data cards were used, read Card 1 on both sides. & & \\
\hline 13 & Repeat Steps $9-12$ for each data card used. & & \\
\hline \multirow[t]{2}{*}{ Note } & (a) If a false timing start occurs, press $R / S$ to stop timing. & $\mathrm{R} / \mathrm{S}$ & $\mathrm{nnn}$ \\
\hline & (b) Press $B$ to reinstate the calculator status for the next trial number. & B & $\mathrm{nn}$ \\
\hline
\end{tabular}

on the lens of the slide projector. (More precise synchronization of circuitry is possible through the use of a solenoid to activate the calculator switch.) Although this adaptation solved one subset of problems arising from our inability to "talk" to the calculator electronically, it is clear that a breakthrough could occur in calculator design if communication with external devices was permitted. Such an advance would permit psychologists access to a low-power inexpensive microprocessor for reaction-time experiments, stimulus timing, and a broad range of other applications.

A second limitation in our application is the absence of a hard-copy output of trial durations. This produces some inconvenience, especially when more than 24 trials are needed, because the duration for the first 24 trials must be stored on a magnetic chip before the experiment can proceed. We have not found this to be a major problem. However, if a hard copy is necessary, Hewlitt-Packard makes the HP-67 with a printer in their more expensive Model HP-97. (Also, see Footnote 1.) The only problem is that the HP-97 is more bulky and less suitable than the HP-67 for field applications.

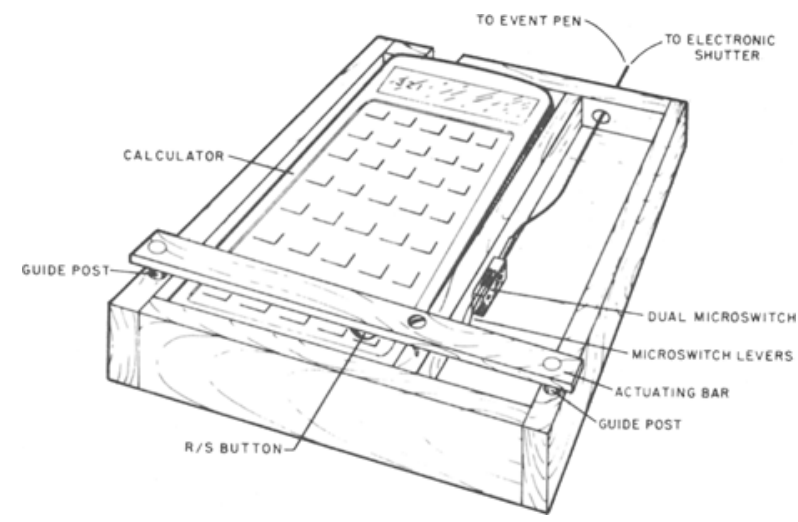

Figure 1. Line drawing of calculator and cradle used to synchronize timing with other experimental events.

\section{OTHER APPLICATIONS}

Obviously, the programmable calculator can be used for a wide variety of other applications that require timing of observations and storage of time values, whether or not intertrial compuations are necessary. A slight modification of the present program converts the calculator into a simple timing and storage device and reduces the intertrial overhead time required for criterion calculations. For experiments requiring fewer than 24 trials, only the instruction in Step 139 need be deleted (or replaced by a space), so that the criterioncalculating section of the program (Steps 141-196) is skipped. If more than 24 trials are needed, the experimenter may also want to change the contents of Step 205 to " 0 " instead of " 5 " and delete Steps 207-210. This operation will free Memory Locations 1-5 for storage after Trial 24.

One note of warning: The HP calculator is sensitive to electromagnetic fields that might be produced by logic-switching components in psychological experiments. A solution is to keep the calculator a respectable distance from such equipment. Another possibility is to encase the calculator in a grounded metal cradle.

\section{REFERENCES}

Caron, A. J., Caron, R. F., \& Carlson, V. R. Do infants see objects or retinal images? Shape constancy revisited. Infant Behavior and Development, in press.

Celhoffer, L., Boukydis, C., Minde, K., \& Muir, E. The DCR-II event recorder: A portable high-speed digital cassette system with direct computer access. Behavior Research Methods \& Instrumentation, 1977, 9, 442-446.

Scotr, K. G., \& MASI, W. S. Use of Datamyte in analyzing duration of infant behaviors. Behavior Research Methods \& Instrumentation, 1977, 9, 429-433.

\section{NOTES}

1. For a variety of reasons, including programming ease and quality, we prefer the HP-67 calculator. However, other cal- 
culators, such as the Texas Instruments TI-59, could be used. The TI-59 is less expensive than the HP-67 and has the advantages of more memory storage and an option which permits it to be plugged into a small printer.

2. This procedure produced the greatest number of counts/ sec. A single-step reverse loop can be used to conserve memory, but only about 5.5 counts/sec are possible. Note that the I register, which is used as an indirect register to store looking durations after trials, is also used (Step 126) during timing as a reverse-step register. The I register assumes this latter function when its value is negative.
3. The number of counts/sec changes slightly on our calculator, dropping about 1 count/sec over the range from 5 to $105 \mathrm{sec}$. Although additions to the program could be made to compensate the change, timing accuracy within this range is $\pm 3 \%$ using the standard division of 20 counts/sec, less than random variation in the typical oberver's reaction time. The count rate does not depend on whether battery or line power is used or on the charge level of the battery.

(Received for publication May 2, 1978; revision accepted December 28,1978 .) 